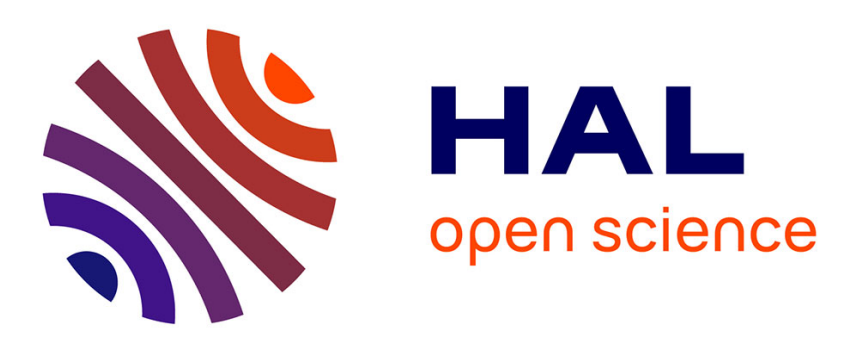

\title{
Magnetic circular dichroism of colour centres in CaF2 : $\mathrm{Na}$
}

\author{
J.L. Doualan, J. Margerie, F. Martin-Brunetière, E. Rzepka
}

\section{To cite this version:}

J.L. Doualan, J. Margerie, F. Martin-Brunetière, E. Rzepka. Magnetic circular dichroism of colour centres in CaF2: Na. Journal de Physique Lettres, 1983, 44 (10), pp.375-385. 10.1051/jphyslet:019830044010037500 . jpa-00232206

\section{HAL Id: jpa-00232206 https://hal.science/jpa-00232206}

Submitted on 1 Jan 1983

HAL is a multi-disciplinary open access archive for the deposit and dissemination of scientific research documents, whether they are published or not. The documents may come from teaching and research institutions in France or abroad, or from public or private research centers.
L'archive ouverte pluridisciplinaire HAL, est destinée au dépôt et à la diffusion de documents scientifiques de niveau recherche, publiés ou non, émanant des établissements d'enseignement et de recherche français ou étrangers, des laboratoires publics ou privés. 
Classification

Physics Abstracts

$61.70 \mathrm{D}-78.20 \mathrm{~L}$

\title{
Magnetic circular dichroism of colour centres in $\mathrm{CaF}_{2}: \mathbf{N a}$
}

\author{
J. L. Doualan, J. Margerie, F. Martin-Brunetière, \\ Laboratoire de Spectroscopie Atomique (*), Université de Caen, 14032 Caen Cedex, France \\ and E. Rzepka \\ Laboratoire de Physique Cristalline (*), Université Paris-Sud, 91405 Orsay Cedex. France
}

(Reçu le 22 février 1983, accepté le 28 mars 1983)

\begin{abstract}
Résumé. - Le dichroïsme circulaire magnétique(D.C.M.) de différents centres colorés dans $\mathrm{CaF}_{2}: \mathrm{Na}$ coloré additivement a été mesuré à différentes températures, dans le domaine 1,65-195 $\mathrm{K}$. Les bandes d'absorption 612,435 et $382-385 \mathrm{~nm}$ sont associées à des D.C.M. paramagnétiques importants, ce qui prouve qu'elles proviennent très probablement de centres à nombre impair d'électrons. $612 \mathrm{~nm}$ ne peut donc pas être seulement une transition du centre $F_{2 A}$ orienté $[1,0,0]$ comme on l'admet habituellement. D'autre part, la bande $490 \mathrm{~nm}$ ne possède qu'un D.C.M. diamagnétique. Nous discutons quelques identifications possibles pour les principales bandes d'absorption des centres colorés dans $\mathrm{CaF}_{2}: \mathrm{Na}$, mais il faut, pour arriver à des conclusions sûres, d'autres travaux utilisant des techniques complémentaires.
\end{abstract}

\begin{abstract}
The magnetic circular dichroism (M.C.D.) of several centres in additively coloured $\mathrm{CaF}_{2}: \mathrm{Na}$ has been measured as a function of temperature in the $1.65-195 \mathrm{~K}$ range. The 612,435 and $382-385 \mathrm{~nm}$ bands display significant paramagnetic M.C.D. signals, which proves that they most probably arise from centres with an odd number of electrons. Thus $612 \mathrm{~nm}$ cannot be only a transition of the $[1,0,0]$ oriented $F_{2 A}$ centre, as currently assumed. On the other hand, the $490 \mathrm{~nm}$ band only shows a diamagnetic M.C.D. We tentatively discuss some possible assignments for the chief absorption bands of colour centres in $\mathrm{CaF}_{2}: \mathrm{Na}$, but further work using complementary techniques is clearly necessary before one comes to a reliable conclusion.
\end{abstract}

\section{Introduction.}

Colour centres in pure $\mathrm{CaF}_{2}$ have been extensively studied, both theoretically and experimentally, particularly at the Clarendon Laboratory [1], and they are now reasonably well understood : several centres have been reliably identified by their absorption and fluorescence bands, by their zero-phonon lines, by their E.P.R. and ENDOR spectra...

As is well known, colour centres in fluorite are very sensitive to impurities. Thus, the optical spectra of coloured pure $\mathrm{CaF}_{2}$ and of coloured $\mathrm{CaF}_{2}$ with a few $10^{-4}$ or $10^{-3} \mathrm{Na}$ doping (of interest as a colour centre laser material [2]) are wholly different. It is therefore quite natural to

$\left(^{*}\right)$ Associés au C.N.R.S. 
assign the chief transitions observed in $\mathrm{CaF}_{2}: \mathrm{Na}$ to $\mathrm{F}$ centre aggregates associated with a sodium impurity. Thus, Lisitsyn and Shtanko [3] ascribe the 385 and $435 \mathrm{~nm}$ absorption bands to the $F_{A}$ centre, i.e. an anion vacancy decorated by an electron with a nearest neighbour $\mathrm{Ca}^{++}$replaced by an $\mathrm{Na}^{+}$impurity (Fig. 1a). Rauch [4] attributes the conspicuous absorptions at 382 and $612 \mathrm{~nm}$ and emission at $755 \mathrm{~nm}$ to the $F_{2 A}$ centre, which consists of two neighbouring fluorine vacancies, aligned along a $[1,0,0]$ direction, decorated with two electrons and close to a $\mathrm{Na}^{+}$ substitutional impurity [2] (Fig. 1b). Polarization of fluorescence shows the 612 and $755 \mathrm{~nm}$ transitions to be orientated along the $[1,0,0]$ axis of the defect and the $382 \mathrm{~nm}$ band perpendicularly. Rauch [4] also describes two $\mathrm{F}_{3 \mathrm{~A}}^{+}$centres (Fig. $1 c$ [5] and 1d) constituted of three fluorine vacancies decorated by only two electrons. One of them is linear along a $[1,0,0]$ direction, with absorption at 490 and fluorescence at $554 \mathrm{~nm}$. In the other one, the three vacancies form a right angled isosceles triangle; the absorption is at $450 \mathrm{~nm}$, the emission at $505 \mathrm{~nm}$.

Obviously other, yet unidentified, centres contribute to the observed absorption and emission spectra, with severe problems of overlaps between bands of different origins. Moreover, the above reported assignments rest on much less extensive evidence than those of the bands in pure $\mathrm{CaF}_{2}$. We therefore thought worthwhile (as a part of our colour centre research program) to investigate more systematically the identifications of colour centres in $\mathrm{CaF}_{2}: \mathrm{Na}$, jointly using several techniques, including excitation spectra, fluorescence polarization, linear dichroism induced by polarized light bleach, study of zero phonon lines, magnetic circular dichroism (M.C.D.). The aim of the present letter is to report some rather unexpected results we have obtained, chiefly by the latter technique. Section 2 will deal with the experimental methods, section 3 with the optical absorption spectra, section 4 with our M.C.D. results and section 5 with the discussion, including tentative assignments of the chief optical bands in $\mathrm{CaF}_{2}: \mathrm{Na}$.

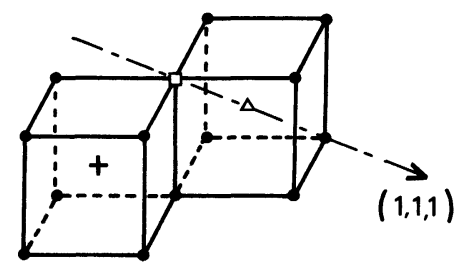

a

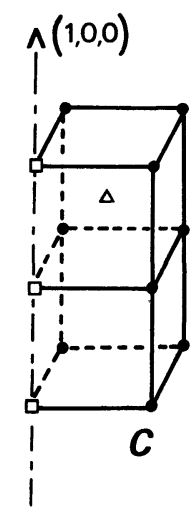

Fig. 1. - Configuration of various colour centres in $\mathrm{CaF}_{2}: \mathrm{Na} . \bullet=\mathrm{F}^{-} ; \square=\mathrm{F}^{-}$vacancy; $+=\mathrm{Ca}^{++}$; $\Delta=\mathrm{Na}^{+} .1 a: \mathrm{F}_{\mathrm{A}}$ centre (if the vacancy is decorated with one electron). $1 b: \mathrm{F}_{2 \mathrm{~A}}$ or $\mathrm{F}_{2 \mathrm{~A}}^{+}$centre depending on whether the vacancies are decorated with two or one electron(s). $1 c$ : Linear $\mathrm{F}_{3 \mathrm{~A}}^{+}$centre (the vacancies are decorated with two electrons). $1 d$ : Angular $\mathrm{F}_{3 \mathrm{~A}}^{+}$centre (the vacancies are decorated with two electrons). 


\section{Experimental methods.}

The work was performed partly in Orsay (crystal growth by a Bridgman method, spectroscopic study of colour centres in X-rayed samples), partly in Caen (spectroscopic study of additively coloured samples and M.C.D. experiments).

Absorption spectra were measured at Orsay with a Cary $14 \mathrm{R}$ in the whole $250-750 \mathrm{~nm}$ range, whereas the home-made Caen absorption and M.C.D. apparatus had an U.V. cut off at $\sim 360 \mathrm{~nm}$. The main part of this latter equipment has already been described [6]; the chief recent improvement is the on-line use of a Tandy TRS 80 microcomputer which controls the monochromator through a stepping motor, registers the optical absorption or M.C.D. data and performs part of their analysis.

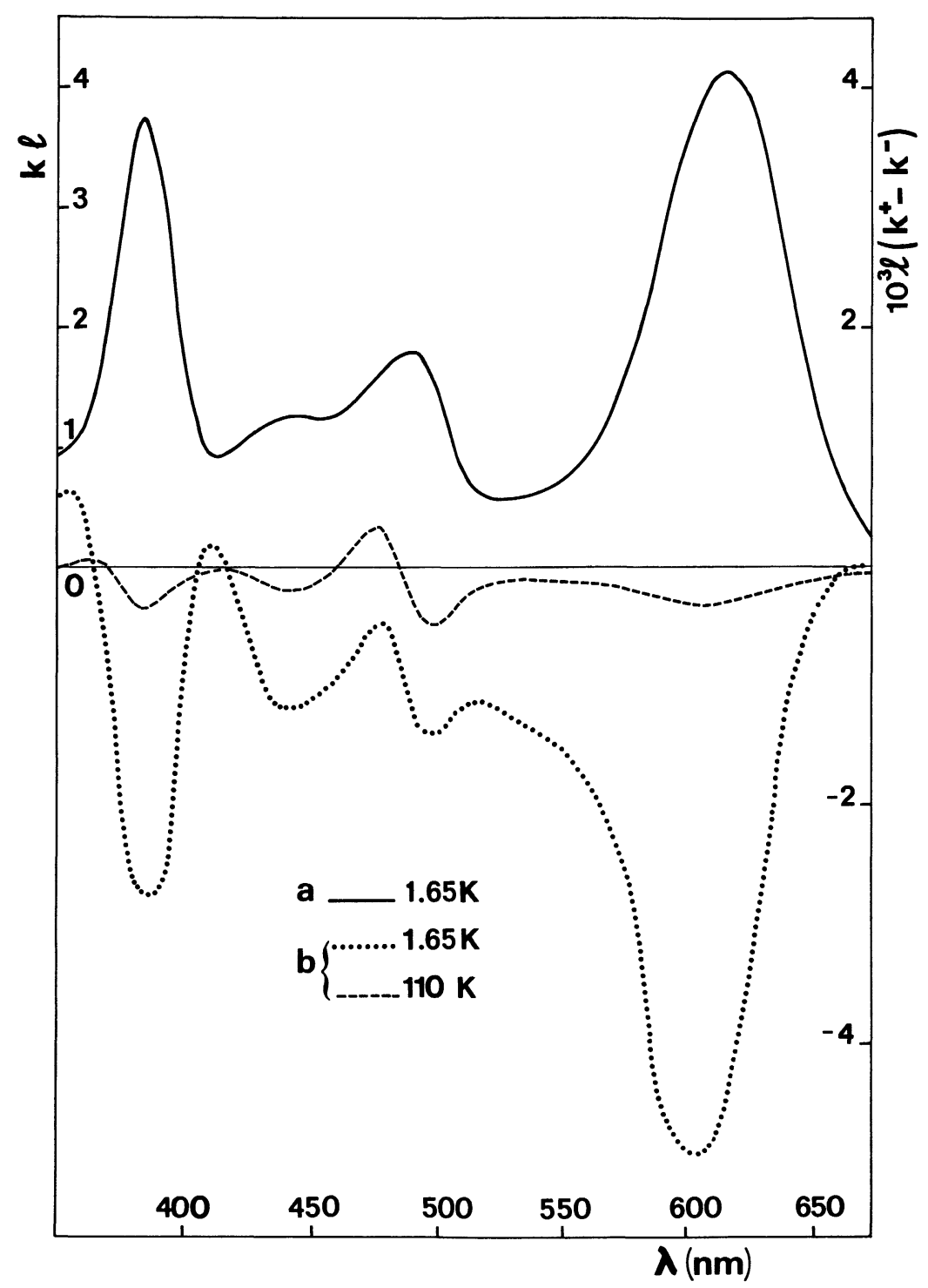

Fig. 2. $-2 a$ : Absorption spectrum (left scale) at $1.65 \mathrm{~K}$ of an additively coloured sample (200 ppm of $\mathrm{Na}$ ) in its " blue " state (see text). $2 b$ : M.C.D. (right scale) of the same sample in the same state, in a $0.89 \mathrm{~T}$ field, at $1.65 \mathrm{~K}(\ldots)$ and $110 \mathrm{~K}(---)$. 
We used samples from 3 different crystals with sodium contents, respectively 200, 290 and 770 p.p.m. as determined by COGEMA through emission spectroscopy. X-ray coloration was performed either at $77 \mathrm{~K}$ or room temperature by a tube with a tungsten anticathode and a beryllium window, operated under $50 \mathrm{kV}$ voltage. For additive coloration, the samples were heated at $\sim 700^{\circ} \mathrm{C}$ in a calcium atmosphere, inside sealed silica bulbs, and then quenched by dropping the bulbs into liquid nitrogen.

\section{Absorption spectra.}

3. 1 AdDitively COlOURED SAMPLeS. - Atter the latter described treatment, the absorption spectrum consists of several poorly resolved bands, but it does not contain the $612 \mathrm{~nm}$ band of chief interest to us. As recommended by [5], we therefore irradiated the samples for several hours at room temperature with near U.V. light (Osram 1.2 A Hg lamp, Schott UG 11 filter). We thus obtained a «blue » sample, with the low temperature absorption spectrum of figure $2 a\left({ }^{1}\right)$.

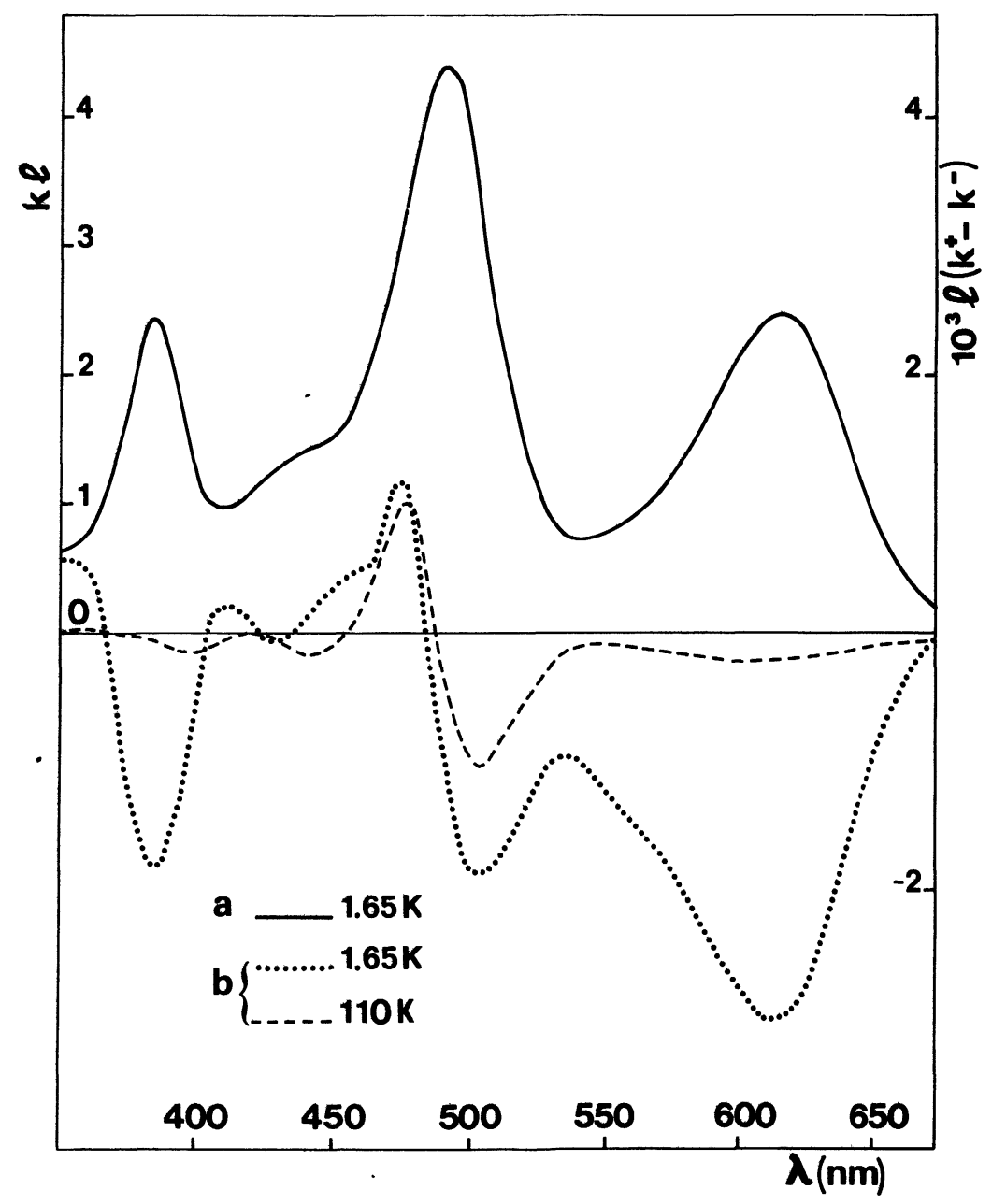

Fig. 3. - Same as figure 2, but with the sample in its « violet » state.

( $\left.{ }^{1}\right)$ Throughout this text, we refer to the 385 and $435 \mathrm{~nm}$ bands, like reference [3], and to the 382,490 and $612 \mathrm{~nm}$ bands, like reference [4], although there are some slight differences between these wavelengths and the positions of absorption maxima in our own spectra. The discrepancies may arise from experimental errors on either part; from variations of the absorption wavelengths with the temperature; from some bands being unresolved absorptions of different centres, the proportion of which may vary from sample to sample. 
This spectrum may be altered in several ways among which we shall only need below the following ones :

a) Spontaneously, at room temperature in a few days and at $100^{\circ} \mathrm{C}$ in less than one hour, the crystal turns to "violet», i.e. its low temperature absorption spectrum becomes the one of figure $3 a$ [5], with an increase of the $490 \mathrm{~nm}$ band at the expense of the 612 and $382 \mathrm{~nm}$ bands. The reverse transformation (spectrum $3 a \rightarrow$ spectrum $2 a$ ) is obtained by room temperature irradiation with near U.V. light during one or two hours.

b) At liquid nitrogen temperature, the samples are indefinitely stable in the dark, but they may be made "yellow » by irradiation with near U.V. light. The $612 \mathrm{~nm}$ band bleaches first, then the $490 \mathrm{~nm}$ band. Simultaneously, the $435 \mathrm{~nm}$ band grows and the near U.V. spectrum is

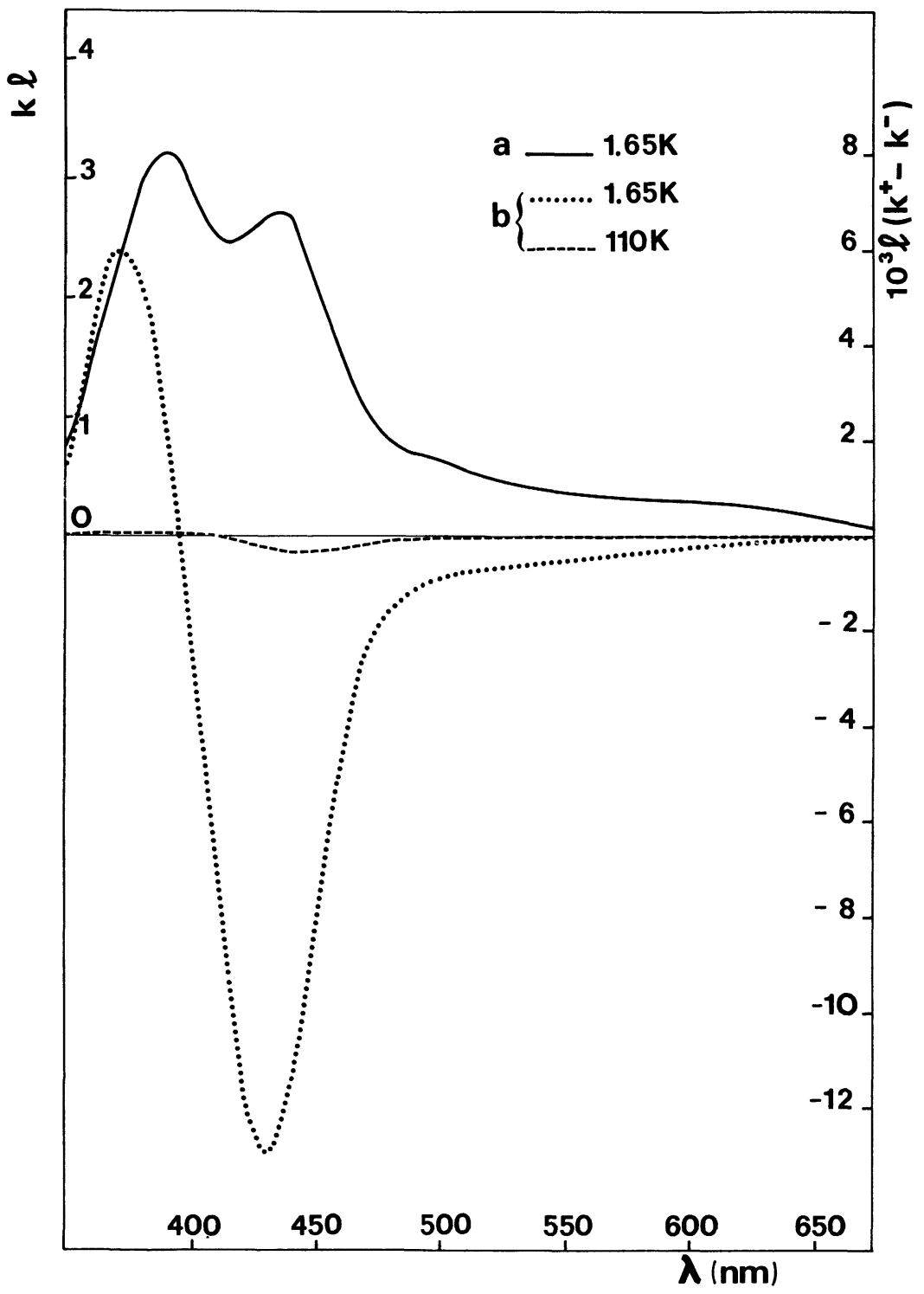

Fig. 4. - Same as figure 2, but with the sample in its " yellow » state. The M.C.D. scale differs from the one of figures $2 b$ and $3 b$ by a factor 2.5 . 
slightly modified (the absorption band broadens somewhat and its top shifts by approximately $6 \mathrm{~nm}$ towards longer wavelengths). Figure $4 a$ shows the $1.65 \mathrm{~K}$ absorption spectrum of the sample after a nearly thorough bleach at $77 \mathrm{~K}$ by near U.V. light. The reverse transformation (spectrum $4 a \rightarrow$ spectrum $2 a$ ) is obtained by merely raising the sample temperature up to $\sim 195 \mathrm{~K}$ (or above).

It should be stressed that the three spectra of figures $2 a, 3 a$ and $4 a$ (as well as intermediate ones) may be obtained in turn with the same sample any number of times without any noticeable loss of coloration, which is quite natural for an additively coloured crystal. We have quoted here these results about the bleaching properties of colour centres in $\mathrm{CaF}_{2}: \mathrm{Na}$ because they are useful for the understanding of our M.C.D. experiments; we postpone to another publication the full report of our work in this domain.

3.2 X-RAYED SAMPLES. - After X-ray irradiation at $77 \mathrm{~K}$, the absorption spectrum is of the " yellow » type, without the remainders of 612 and $490 \mathrm{~nm}$ bands of figure $4 a$, but with some additional features arising from $\mathrm{V}_{\mathrm{K}}$ or $\mathrm{V}_{\mathrm{H}}$ centres.

Annealing at $295 \mathrm{~K}$ this low temperature irradiated sample, one obtains, upon cooling back to low temperatures, a « blue » spectrum (see Fig. 5), purer than the one of figure $2 a$ (no $490 \mathrm{~nm}$ band). One observes, besides the 382 and $612 \mathrm{~nm}$ peaks, a third maximum, further in the U.V. at $326 \mathrm{~nm}$ (which may also exist in the case of Fig. $2 a$, but which is out of the spectral domain of the Caen apparatus). A spectrum similar to the one of figure 5 may also be obtained by X-ray irrádiation at room temperature.

Finally, a " violet " spectrum may be obtained by a $95^{\circ} \mathrm{C}$ annealing of a room temperature $\mathrm{X}$-irradiated sample. It presents some differences with the « violet » spectrum of figure $3 a$, but we shall not discuss them here any further as they have no incidence on the main topic of the present letter.

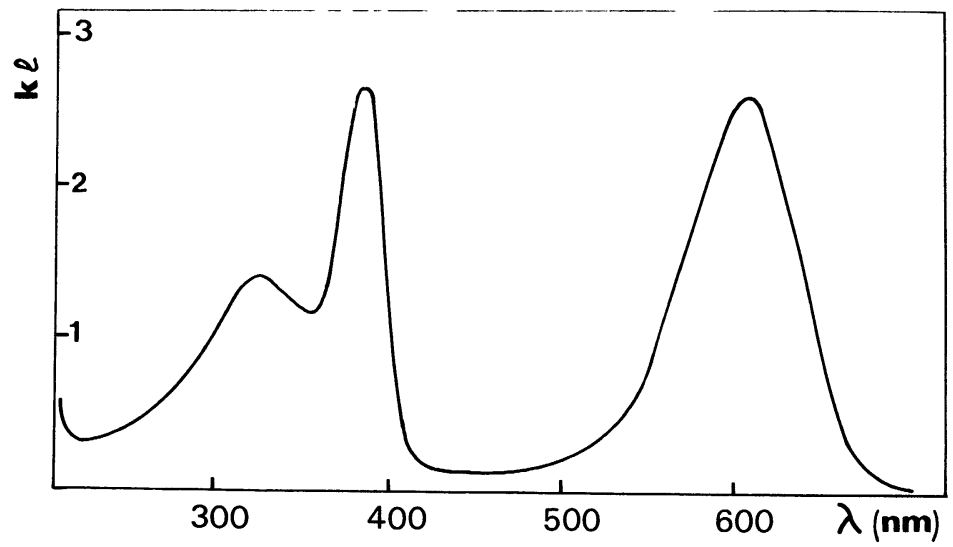

Fig. 5. - Absorption at liquid nitrogen temperature of a sample (770 p.p.m. of $\mathrm{Na}$ ) which has been $\mathrm{X}$ irradiated at $77 \mathrm{~K}$, then annealed for $10 \mathrm{~min}$. at room temperature.

\section{Magnetic circular dichroism.}

Let $l$ be the sample thickness, $k^{+}$and $k^{-}$its absorption coefficients for $\sigma^{+}$and $\sigma^{-}$light respectively. We have measured the M.C.D. $l\left(k^{+}-k^{-}\right)$at $1.65,110$ and $195 \mathrm{~K}$ in a $0.89 \mathrm{~T}$ magnetic field. It is plotted in figures $2 b, 3 b$ and $4 b$ for states of the sample corresponding to the absorption spectra of figures $2 a, 3 a$ and $4 a$ respectively $\left({ }^{2}\right)$. The following observations may be made :

( $\left.{ }^{2}\right) 195 \mathrm{~K}$ data are not shown on the figures for the sake of clarity. Similar results were also obtained with other sodium contents in the sample, as well as with an X-rayed crystal. 
4.1 The $612 \mathrm{~nm}$ band has nearly the same shape in the optical absorption and in the M.C.D. spectra (the M.C.D. band however has a somewhat more extended blue wing). We define the " relative dichroism " :

$$
\rho=\frac{k^{+}-k^{-}}{k^{+}+k^{-}}
$$

The observed values of $\rho$ are listed in table I along with the estimated accuracy; the chief error arises from the complexity of the spectrum and partial overlap of bands from different centres. Within this accuracy, the observed relative dichroism does not depend on the magnitude of the optical absorption : for instance, it is the same in figures 2 and 3.

When one suddenly modifies the value of the magnetic field $H_{0}$, the M.C.D. of the sample at $1.65 \mathrm{~K}$ does not "follow " immediately. It varies exponentially with a time constant $T_{1}$ of $170 \pm 20$ seconds $\left({ }^{3}\right)$. This behaviour, together with the temperature variation of the M.C.D. (see Table I), demonstrates that a paramagnetic specie is responsible for at least a significant part of the $612 \mathrm{~nm}$ absorption band, $T_{1}$ being the spin-lattice relaxation time of the degenerate ground level of this species.

Table I. - Magnetic circular dichroism for $H_{0}=0.89$ tesla of the main absorption bands in additively coloured $\mathrm{CaF}_{2}: \mathrm{Na}$. Parameters $\rho$ and $r$ are defined by equations (1) and (2) of the text. Calculated values of $\rho$ were obtained from formula

$$
\rho=\left[-\frac{A}{2} \operatorname{th}\left(\frac{g_{\mathrm{s}} \beta H_{0}}{2 k T}\right)+g \beta H_{0}\right]\left(\frac{1}{E_{i}-E_{j}}+\frac{1}{E_{i}-E_{j^{\prime}}}\right)
$$

where $\beta$ is the Bohr magneton, $k$ the Boltzmann constant, $T$ the temperature, $q$, the $g$-factor of the $\mathrm{s}$-like ground state (assumed to be equal to 2.0). $E_{i}$ is the energy of the excited level of interest, $E_{j}$ and $E_{j^{\prime}}$ are the energies of the two other levels arising from the splitting of the p-like excited state. For the $\mathrm{F}_{\mathrm{A}}$ centre, we assumed $E_{i}=22990 \mathrm{~cm}^{-1}, E_{j}=E_{j^{\prime}}=25970 \mathrm{~cm}^{-1}$ from the absorption spectrum; $A_{1}=-23 \mathrm{~cm}^{-1}, g_{1}=0.07$ to fit our M.C.D. data. The « $\mathrm{Y}$ » centre has been assumed to be $\mathrm{F}_{2 \mathrm{~A}}^{+}$, as tentatively suggested in section 5.3, with the following values of the parameters : $E_{i}$, $E_{j}=16340,26180 \mathrm{~cm}^{-1}, E_{j^{\prime}}=30670 \mathrm{~cm}^{-1}$ from the absorption spectrum; $A_{3}=-23 \mathrm{~cm}^{-1}$,

\begin{tabular}{|c|c|c|c|c|}
\hline & $\begin{array}{c}10^{5} \rho \\
\text { (612 nm band) } \\
\text { «Y } »\end{array}$ & $\begin{array}{c}10^{5} \rho \\
(435 \mathrm{~nm} \text { band }) \\
\mathrm{F}_{\mathrm{A}}\end{array}$ & $\begin{array}{c}10^{5} \rho \\
\text { (382 nm band) } \\
\text { «Y } »\end{array}$ & $\begin{array}{c}r\left(\mathrm{~cm}^{-1}\right) \\
(490 \mathrm{~nm} \text { band }) \\
« \mathrm{X} »\end{array}$ \\
\hline $1.65 \mathrm{~K}\left\{\begin{array}{l}\text { obs } \\
\text { calc }\end{array}\right.$ & $\begin{array}{l}-65 \pm 4 \\
-71\end{array}$ & $\begin{array}{l}-270 \pm 70 \\
-270\end{array}$ & $\begin{array}{l}-62 \pm 10 \\
-50\end{array}$ & $-0.22 \pm 0.02$ \\
\hline $110 \mathrm{~K}\left\{\begin{array}{l}\text { obs } \\
\text { calc }\end{array}\right.$ & $\begin{array}{l}-4.0 \pm 0.5 \\
-4.0\end{array}$ & $\begin{array}{l}-6 \pm 1.5 \\
-6.1\end{array}$ & $\begin{array}{l}-3 \pm 1 \\
-2.8\end{array}$ & $-0.22 \pm 0.02$ \\
\hline $195 \mathrm{~K}\left\{\begin{array}{l}\text { obs } \\
\text { calc }\end{array}\right.$ & $\begin{array}{l}-\quad 3.3 \pm 0.5 \\
-\quad 3.5\end{array}$ & $-\quad 4.3$ & $\begin{array}{l}-3 \pm 1 \\
-2.5\end{array}$ & $-0.24 \pm 0.02$ \\
\hline
\end{tabular}
$g_{3}=0.41$ to fit our M.C.D. data.

$\left(^{3}\right)$ This value of $T_{1}$ corresponds to a field $H_{0}$ of 0.89 tesla. $T_{1}$ decreases slowly with $H_{0}$ and equals $60 \mathrm{~s}$ for $H_{0}=0.05$ tesla. 
4.2 The $435 \mathrm{~nm}$ band has a similar paramagnetic behaviour (see Fig. 4 and Table I). When one modifies the magnetic field at $1.65 \mathrm{~K}$, the $435 \mathrm{~nm}$ M.C.D. varies with a time constant $T_{1}^{\prime}$ of $160 \pm 20$ seconds (in a 0.89 tesla field). The difference between $T_{1}$ and $T_{1}^{\prime}$ is not significant.

4.3 In the near ultraviolet, observed M.C.D. phenomena are somewhat more complex. For « blue " samples (Fig. 2), one chiefly observes an absorption shaped M.C.D., the $\rho$ of which are listed in table I. The corresponding time constant at $1.65 \mathrm{~K}$ is close to the $T_{1}$ of the $612 \mathrm{~nm}$ band ; unfortunately an accurate measurement was impossible because of a too poor signal to noise ratio : our light source is not intensive enough in the near ultraviolet.

When the sample is in the " yellow » condition (Fig. 4), we again observe a paramagnetic signal, but with a positive sign and with a maximum noticeably shifted $(21 \mathrm{~nm})$ toward shorter wavelengths with respect to the absorption band maximum. The time constant of the low temperature transients at $370 \mathrm{~nm}$ is similar to the $T_{1}^{\prime}$ of the $435 \mathrm{~nm}$ band but, again, poor signal to noise ratio in the U.V. region prevents a precise comparison.

4.4 The M.C.D. associated with the $490 \mathrm{~nm}$ band is quite different from all previous ones : it is clearly dispersion shaped, positive in the short wavelength wing and negative in the long wavelength one (Figs. $3 b$ and $4 b$ ). It can therefore be compared with the derivative of the absorption curve with respect to the wavenumber $\sigma$. More precisely, we divide both experimental curves by $\sigma$, consistently with Henry et al.'s [7] theoretical analysis, and we compare $\frac{l\left(k^{+}-k^{-}\right)}{\sigma}$ with $l \frac{\mathrm{d}}{\mathrm{d} \sigma}\left(\frac{k^{+}+k^{-}}{\sigma}\right)$. The agreement is not so good that the one between absorption and dichroism curves in the $612 \mathrm{~nm}$ region : the D.C.M. curve is shifted by $\sim 6 \mathrm{~nm}$ to the blue of the absorption derivative and it is somewhat sharper. We introduce the « best » ratio $r$ by :

$$
r=\frac{\left[\left(k^{+}-k^{-}\right) / \sigma\right]_{\text {peak to peak }}}{\left[\frac{\mathrm{d}}{\mathrm{d} \sigma}\left\{\left(k^{+}+k^{-}\right) / \sigma\right\}\right]_{\text {peak to peak }}} .
$$

Parameter $r$ is given in the last column of table I for 1.65, 110 and $195 \mathrm{~K}$. One may remark that it is indeed independent of the temperature $\left({ }^{4}\right)$. Moreover, it does not depend of the "state " of the sample, i.e. on the magnitude of the $490 \mathrm{~nm}$ absorption. Finally, when one modifies the value of $H_{0}$, the M.C.D. associated with the $490 \mathrm{~nm}$ band changes " immediately ", even at pumped helium temperatures (i.e. it is observed to vary with the instrumental time constant of a few seconds). All these observations suggest an M.C.D. of purely diamagnetic origin.

\section{Discussion.}

5.1 The " yellow » spectra of figure 4 are consistent with Lisitsyn and Shtanko's [3] identification of the $\mathrm{F}_{\mathrm{A}}$ centre absorption at 380 and $435 \mathrm{~nm}$. C.H. Henry et al. [7, 8] have studied both theoretically and experimentally the M.C.D. of $\mathrm{F}_{\mathrm{A}}$ centres in $\mathrm{KCl}$ : they found an absorption shaped negative signal at the location of the long wavelength band (polarized parallel to the defect axis) and the superposition of absorption and dispersion shaped signals at the location of the short wavelength band (polarized perpendicular to the defect axis) $\left({ }^{5}\right)$. This is nearly exactly what

$\left({ }^{4}\right)$ When temperature increases, the $490 \mathrm{~nm}$ absorption band broadens and its maximum decreases. This explains how parameter $r$ may be temperature independent, while $\left[\left(k^{+}-k^{-}\right) / \sigma\right]_{\text {peak to peak }}$ is smaller at $110 \mathrm{~K}$ than at $1.65 \mathrm{~K}$ (see Fig. $3 b$ ).

$\left.{ }^{5}\right)$ The geometry of $\mathrm{F}_{\mathrm{A}}$ centres is not the same in the $\mathrm{KCl}$ and in the $\mathrm{CaF}_{2}$ lattices $\left(\mathrm{C}_{4 \mathrm{v}}\right.$ symmetry in the former case, $C_{3 v}$ in the latter) but it makes no difference in the predicted M.C.D., at least if one uses « isotropic » samples, i.e. without a previous alignment of the $F_{A}$ centres in a preferential direction. 
appears in figure $4 b$ for $\mathrm{CaF}_{2}: \mathrm{Na}$ at helium temperature. There is a negative, absorption shaped signal at $435 \mathrm{~nm}$; the positive maximum at $374 \mathrm{~nm}$, shifted towards shorter wavelengths with respect to the absorption maximum may arise from the dispersion shaped component of the M.C.D. in the perpendicularly polarized band. Presumably the negative minimum of the dispersion shape is lost in the wing of the $435 \mathrm{~nm}$ centred signal. Henry et al.'s [7] theory predicts equal areas for the positive and negative lobes of the $F_{A}$ centre M.C.D. This is not the case of the data of figure $4 b$ : the positive lobe is too weak (even when one takes into account the change from wavelength to wavenumber abcissa scale and when one divides the observed dichroisms by $\sigma$ ). We do not know the reason for it. Maybe there is in the $380 \mathrm{~nm}$ region another band with a negative absorption shaped M.C.D. which shifts all observed M.C.D. data toward the bottom. Numerically, the M.C.D. of the $435 \mathrm{~nm}$ peak may be calculated from the formula quoted in the caption of table I. The temperature dependence of this formula allows determination of two parameters of the unrelaxed excited state of the $\mathrm{F}_{\mathrm{A}}$ centre : its orbital $g$-factor $g_{1} \simeq 0.07$ and its spin orbit coupling constant $A_{1} \simeq-23 \mathrm{~cm}^{-1}$. These parameters are of the same order of magnitude, although somewhat smaller, than the corresponding ones for $\mathrm{F}$ centres in pure $\mathrm{CaF}_{2}\left(g_{\text {orb }}=0.29\right.$ and $A=\frac{2}{3} \times(-41.7)=-28 \mathrm{~cm}^{-1}$ according to Roger et al. [9]).

5.2 The rather narrow $490 \mathrm{~nm}$ absorption band is associated with an obviously diamagnetic dispersion shaped signal (section 4.4). This suggests a centre (we shall call it « $X$ ») with a singlet ground level and a doubly or triply degenerate (or nearly degenerate) excited state. This is only partly consistent with Rauch's [4] assignment of a linear $\mathrm{F}_{3 \mathrm{~A}}^{+}$centre : this two electrons defect should be non-paramagnetic (as observed), but its longer wavelength $490 \mathrm{~nm}$ transition should have a non degenerate excited state (contrarily to the observed M.C.D. spectrum). Let us add that our polarized bleaching experiments do not support one of Rauch's [4] conclusions based on fluorescence polarization experiments : the $490 \mathrm{~nm}$ transition dipole of the "X " centre is not oriented along $[1,0,0]$ axes, since no linear dichroism is induced by partial bleach of an X-rayed sample with $490 \mathrm{~nm}$ light polarized parallel to one of the $[1,0,0]$ directions.

The values of $r$ listed in table I suggest that the " $\mathrm{X}$ » centre, whatever may it be, has an unrelaxed excited state $g$ factor $g_{2}=0.55 \pm 0.05$, again a reasonable order of magnitude for an electron excess colour centre in a fluorite (or fluorite-like) lattice.

5.3 The results of section 4.1 demonstrate that the centre responsible for the $612 \mathrm{~nm}$ band has a paramagnetic ground level. More precisely, the $612 \mathrm{~nm}$ absorption may be the unresolved superposition of transitions due to several centres, among which one at least (let us call it the " $Y$ » centre) has a paramagnetic ground level. " $\mathrm{Y}$ » is not a minor component of the $612 \mathrm{~nm}$ absorption, other wise its observed M.C.D. would be incredibly large (see note $\left({ }^{9}\right)$ ). In fact, « $\mathrm{Y}$ » may be the principal component of the $612 \mathrm{~nm}$ band as suggested by the following facts : within experimental uncertainty, a partial bleach does not alter the ratio $\rho$ of M.C.D. to optical absorption. Moreover, the shapes of the absorption and M.C.D. signals are nearly the same. Thus, if we assumed, for instance, the $612 \mathrm{~nm}$ band to be due with equal weights to a paramagnetic centre " $\mathrm{Y}$ » and to a non paramagnetic centre « $Z$ », we should be obliged to suppose that these quite different centres have nearly exactly the same absorption shape and also the same bleaching rate $\left({ }^{6}\right)$, which is not impossible but which requires two accidental coincidences.

The $382 \mathrm{~nm}$ absorption and M.C.D. signals, most easily observed with a "blue " sample (Fig. 2), may be attributed to the same « $Y$ » centre since they bleach at the same rate than absorption and M.C.D. signals in the $612 \mathrm{~nm}$ region. This is consistent with Rauch's [4] assignment of 382 and $612 \mathrm{~nm}$ absorptions to the same centre. The absorption spectrum of figure 5 strongly suggests that the $326 \mathrm{~nm}$ band also arises from centre "Y $\mathrm{Y}$. It is unfortunate that the short wavelength cut-off of our M.C.D. equipment has prevented us from checking this important

$\left({ }^{6}\right)$ As well with near U.V. light as with intense red light, according to unpublished results of ours. 
point by comparing the bleaching rate of absorption and M.C.D. signals in the $612 \mathrm{~nm}$ and $326 \mathrm{~nm}$ regions.

Now, what may be the microscopic structure of the "Y $"$ centre ? We discuss below several hypotheses, without contending the list to be exhaustive.

5.3.1 If $~ " \mathrm{Y}$ » is the $\mathrm{F}_{2 \mathrm{~A}}$ centre of figure $1 b$ as postulated by Rauch [4], we are obliged to suppose its ground state to be the lowest spin triplet (the lowest spin singlet being metastable). This behaviour would be opposite to the customary one of two electrons colour centres which have a ground spin singlet and a metastable triplet [10].

5.3.2 R. C. Alig [11] predicted, on theoretical grounds, a $F_{A}$ centre lowest transition in the red portion of the spectrum. Thus $F_{A}$ could have been identified as the paramagnetic " $Y$ » species, but for the wrong orientation of its optical axis : $[1,1,1]$ whereas numerous experimental evidence prove the $" \mathrm{Y}$ » centre to have a $[1,0,0]$ axis.

5.3.3 One may also think of a $[1,0,0] \mathrm{F}_{2}$ centre perturbed by an interstitial neutral sodium atom (see Figure $6 b$, to be compared with $6 a$ showing the Rauch's [4] model of the $F_{2 A}$ centre with a substitutional sodium ion). The defect of figure $6 b$, with three electrons, should have a paramagnetic ground state, although elaborate calculations would be necessary to predict its energy levels and its M.C.D. Its symmetry (as well as the one of Fig. 6a, Rauch's model) is in agreement with the observed behaviour of the " $Y$ " centre : orthorhombic with principal axes parallel to $[1,0,0],[0,1,1]$ and $[0,1,-1]$. However, if $« Y »$ is the centre of figure $6 b$, it seems difficult to understand the easy conversion of "blue " to " yellow " condition and conversely (section 3.1, Fig. $2 a$ and $4 a$ ). (Let us recall that the "yellow " spectrum arises from $[1,1,1] \mathrm{F}_{\mathrm{A}}$ centres, Fig. 1a).

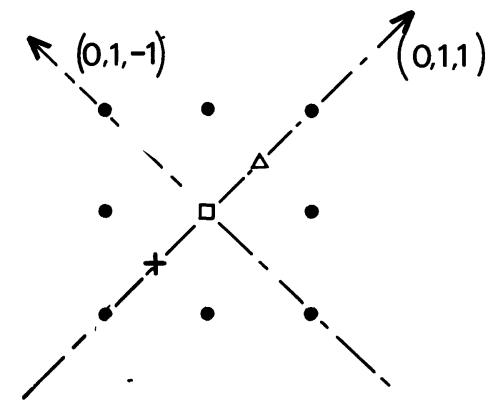

a

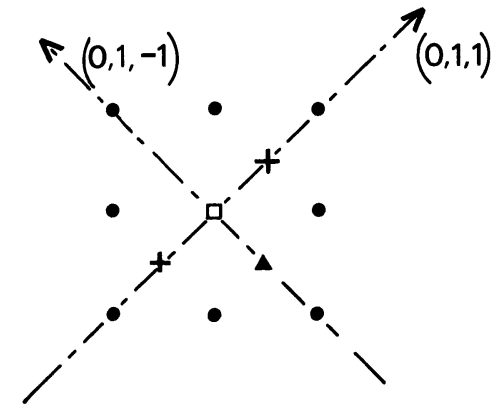

$b$

Fig. 6. - Two possible configurations of $\mathrm{F}_{2 \mathrm{~A}}$ centres : $[1,0,0]$ direction is perpendicular to the figure plane. $\bullet=\mathrm{F}^{-}$ion at heights $+a / 2$ and $-a / 2 ; \square=\mathrm{F}^{-}$vacancy at heights $+a / 2$ and $-a / 2 ;+=\mathrm{Ca}^{++}$ion at height $0 ; \Delta=\mathrm{Na}^{+}$ion at height $0 ; \boldsymbol{\Delta}=\mathrm{Na}$ atom at height $0.6 a$ : Rauch's [4] $\mathrm{F}_{2 \mathrm{~A}}$ centre (the same as in Fig. $1 b$ ). $6 b: \mathrm{F}_{2 \mathrm{~A}}$ centre with an interstitial $\mathrm{Na}$ atom. Both $6 a$ and $6 b$ defects are decorated with two electrons.

5.3.4. Our M.C.D. results are consistent with a model in which the " $Y$ » centre would be $\mathrm{F}_{2 \mathrm{~A}}^{+}$(i.e. the centre of Fig. $1 b$ with only one electron) and the " $\mathrm{X}$ » centre would be $\mathrm{F}_{2 \mathrm{~A}}$ with two electrons. In this hypothesis, the room temperature slow conversion of « $Y$ » to « $X$ » centres in the dark would arise from the neutralization of $\mathrm{F}_{2 \mathrm{~A}}^{+}$into $\mathrm{F}_{2 \mathrm{~A}}$ centres by capture of electrons, slowly released from traps. The room temperature regeneration of « $\mathrm{Y}$ » centres under near U.V. irradiation would be merely the ionization of $\mathrm{F}_{2 \mathrm{~A}}$ centres and capture of the released electrons by by the traps. It is more difficult to explain how the low temperature U.V. irradiation can lead to 
$\mathrm{F}_{2 \mathrm{~A}}^{+} \underset{h v}{\overrightarrow{F_{A}}} \mathrm{~F}_{\mathrm{A}}+\square$ or $\mathrm{F}_{2 \mathrm{~A}} \underset{h v}{\overrightarrow{h v}} \mathrm{~F}_{\mathrm{A}}+\mathrm{F}\left({ }^{7}\right)$. On the other hand, the reverse reactions on raising the temperature to circa $200 \mathrm{~K}$ would merely arise from the vacancies becoming mobile at these temperatures.

The $\mathrm{F}_{2 \mathrm{~A}}^{+}$centre has the requisite symmetry properties to be « $\mathrm{Y}$ » (point group $\left.\mathrm{C}_{2 \mathrm{v}}\right)$. It is expected to have an orbitally non degenerate (s-like) ground state and a p-like excited state, the orbital degeneracy of which is fully lifted by the $C_{2 v}$ crystal field. We may assume that the $[1,0,0]$ component (Fig. $1 b)$ corresponds to energy $E_{1}\left(612 \mathrm{~nm}\right.$ absorption), the $[0,1,1]$ component to energy $E_{2}$ (382 $\mathrm{nm}$ absorption) and the $[0,1,-1]$ component to energy $E_{3}$ (the $326 \mathrm{~nm}$ absorption of Fig. 5) $\left({ }^{8}\right)$. With these assignments, the M.C.D. is predicted to be negative (as observed) for both 612 and $382 \mathrm{~nm}$ bands and to be positive in the $326 \mathrm{~nm}$ region. As may be seen on table I, fair quantitative agreement with experimental data is obtained using the experimental values of $E_{1}, E_{2}, E_{3}$ and assuming, for the unrelaxed excited state of the $\mathrm{F}_{2 \mathrm{~A}}^{+}$centre, a spin orbit coupling constant $A_{3}=-23 \mathrm{~cm}^{-1}$ and an orbital $g$-factor $g_{3}=0.41$. Like in the case of $\mathrm{F}_{\mathrm{A}}$ centres (section 5.1), these parameters are of the same order of magnitude than those of the $F$ centre in pure $\mathrm{CaF}_{2}$ [9], which is quite satisfactory $\left({ }^{9}\right)$.

5. 4 ConCLusion. - Our M.C.D. data allow us to discard the current assignments of some of the most conspicuous absorption bands in sodium doped $\mathrm{CaF}_{2}$. On the other hand they are clearly unable to provide by themselves reliable new assignments. They must be complemented by results from several different techniques before the colour-centres spectrum in $\mathrm{CaF}_{2}: \mathrm{Na}$ may be really said to be understood.

\section{Acknowledgments.}

We are very grateful to Professor J. P. Chapelle for the growth of the $\mathrm{CaF}_{2}: \mathrm{Na}$ crystals we used and for helpful discussions. We also thank Doctor M. Thuau who built most of the M.C.D. apparatus. This research was supported in part by D.R.E.T. (contract no 80/517).

( ${ }^{7}$ ) But it is not easier to understand the same experimental fact with $" Y »=F_{2 A}$ as postulated by Rauch [4].

$\left.{ }^{8}\right)$ W. C. Collins [12] observes 3 absorption bands at 300,360 and $545 \mathrm{~nm}$ in the analogous case of the $\mathrm{F}_{2}^{+}$centre in pure $\mathrm{CaF}_{2}$, even if his discussion refers to 360 and $545 \mathrm{~nm}$ bands only. Similar complete splitting of a p-like excited state was also observed for the $\mathrm{F}_{2}$, centre in $\mathrm{SrCl}_{2}: \mathrm{Rb}^{+}$[13].

$\left({ }^{9}\right)$ If one assumes that the $\mathrm{F}_{2 \mathrm{~A}}^{+}$centres are responsible only for a fraction $f$ of the $612 \mathrm{~nm}$ absorption, the spin-orbit coefficient $A_{3}$ would be $-23 / f \mathrm{~cm}^{-1}$. Thus $f$ cannot be chosen too small; otherwise $A_{3}$ would be incredibly large for a colour centre in a crystal made up of ions with comparatively small spin orbit couplings.

\section{References}

[1] Crystals with the Fluorite Structure, HAYES, W., editor (Clarendon Press, Oxford) 1974, chapter 4 and references within.

[2] Arkhangelskaya, V. A., Fedorov, A. A., Feofilov, P. P., Opt. Commun. 28 (1979) 87.

[3] Lisitsyn, V. M., Shtanko, V. F., Opt. Spectrosc. 42 (1977) 433.

[4] RAUCH, R., Izv. Akad. Nauk. S.S.S.R. Ser. Fiz. 37 (1973) 595.

[5] Arkhangelskaya, V. A., SchCheulin, A. S., Opt. Spectrosc. 50 (1981) 629.

[6] Thuau, M., Margerie, J., C.R. Hebd. Séan. Acad. Sci. 268B (1969) 1586.

ThuAU, M., Thèse d'Etat, Caen (1981).

[7] Henry, C. H., Schnatterly, S. E., Slichter, C. P., Phys. Rev. 137 (1965) A 583.

[8] Henry, C. H., Phys. Rev. 140 (1965) A 256.

[9] Roger, J. P., Lefrant, S., Taurel, L., Billardon, M., Solid State Commun. 18 (1976) 1179.

[10] See, for instance, SeIDEL, H., Phys. Lett. 7 (1963) 27 ;

Hayes, W., Lambourn, R. F., Smith, P. H. S., J. Phys. C 3 (1970) 1797.

[11] Alig, R. C., Phys. Rev. B 3 (1971) 536.

[12] Collins, W. C., Phys. Status Solidi (b) 56 (1973) 291.

[13] Rzepka, E., Baltog, I., Lefrant, S., Yuste, M., Taurel, L., Phys. Status Solidi (b) 57 (1973) 383. 